\title{
PERCEPÇÃO DE PRÉ-ESCOLARES SOBRE SAÚDE BUCAL.
}

\author{
PERCEPTION OF PRE-SCHOOL ON BUCCAL HEALTH.
}

Leonardo dos Santos Antunes*

Lívia Azeredo Alves Antunes**

Marcos Paulo Fonseca Corvino***

\begin{abstract}
RESUMO
Introdução: A participação da pré-escola em conjunto com a família tem fundamental importância no desenvolvimento individual da criança. Assim, este estudo objetivou avaliar as percepções em relação à saúde bucal de 40 crianças do ciclo de Educação Infantil de uma Unidade da rede pública de Ensino de Niterói, RJ. Métodos: Para coleta dos dados foi utilizado um formulário ilustrado e bastante simples que continha figuras dos principais recursos de higiene e de alimentos saudáveis ou não para os dentes. A análise dos dados foi obtida pela frequência (\%) e relação dos mesmos (Teste $\chi^{2}$ e Exato de Fisher) através do programa estatístico SPSS 11.0. Com relação às crianças, $97,5 \%$ marcaram pelo menos um item de higiene bucal; poucos alunos com 4 anos $(5 \%)$ e com 5 anos $(25 \%)$ reconheceram a dieta como um fator representativo para a saúde bucal; houve relaçáo entre a marcação dos alimentos náo saudáveis e a idade das crianças $(\mathrm{P}<0,05)$. Conclusão: Embora a maioria das crianças perceba a importância da higiene bucal, estas náo reconhecem o papel da dieta para a manutenção da saúde, o que vem ao encontro da necessidade de uma maior capacitação dos educadores para orientá-las, maior envolvimento da família nas atividades realizadas na escola e uma participação mais efetiva do dentista na escola através de programas de educação em saúde.
\end{abstract}

DESCRITORES: Educação em saúde bucal - Saúde escolar - Saúde bucal - Promoçâo da saúde

\section{ABSTRACT}

Introduction: The participation of pre-school and the family is very important in the individual development of the child. Thus, this study aimed at evaluating perception on buccal health of 40 childrens in a public pre-school in Niterói, state of Rio de Janeiro. Methods: For collection of the data, a questionary form was used for gathering specific data contained figures showing the most common hygienic resources and those foods which are either healthy or non-healthy for teeth. Data analysis was obtained according to frequency (\%) and relationship (Chi-square test and Fisher's exact test). Regarding to the childrens, at least one item related to oral hygiene was indicated by $97.5 \%$ of them; a few students aged 4 years $(5 \%)$ and 5 years (25\%) knew that diet was a meaningful factor in the oral health; there was a relationship between the non-healthy foods indicated by the children and their ages $(P<0.05)$. Conclusion: It was concluded that although the majority of the children perceives the importance of the buccal hygiene, they do not recognize the paper of the diet for the maintenance of the health, what comes to the meeting of the necessity of a bigger qualification of the educators to guide them, bigger envolvement of the family in the activities carried through the school and a more effective participation of the dentist in the school through programs of education in health.

DESCRIPTORS: Health Education, dental - School health - Oral health - Health promotion.

\footnotetext{
* Mestre em Odontologia pela Universidade Federal Fluminense.

** Mestre em Odontopediatria pela Universidade Federal do Rio de Janeiro.

*** Doutor em saúde Pública pela Universidade de São Paulo - USP, professor adjunto da Universidade Federal Fluminense.
} 


\section{INTRODUÇÃO}

A doença cárie e os problemas periodontais podem influir no desenvolvimento da criança e na sua participaçáo em atividades importantes da vida. A presença de dor, infecção ou disfunção no sistema estomatognático podem restringir o consumo de uma dieta adequada às necessidades energéticas, afetando o crescimento $\mathrm{da}$ criança, bem como o aprendizado, a comunicação e a recreação (American Academy of Pediatric Dentistry ${ }^{1}$, 1995-1996).

Assim, a criança merece uma atenção especial desde os primeiros anos de vida, pois é nessa idade que se estabelece a base para a saúde futura do indivíduo. A saúde deficiente pode constituir um problema não só para a família como também para toda a sociedade.

Segundo Aquilante et al. ${ }^{3}$ (2003), ao se promover saúde nas escolas, incentivando as esperanças e as aptidóes das crianças e adolescentes, o potencial de criar um mundo melhor torna-se ilimitado, uma vez que, se estão saudáveis, podem aproveitar ao máximo toda a oportunidade de aprender.

Nesse contexto, a escola, em conjunto com a família, passam a ter uma importante participação no desenvolvimento individual da criança, visto que essa fica grande parte de seu tempo nessa instituição, que se torna um ambiente importante para o desenvolvimento de hábitos saudáveis (Pomarico et al. ${ }^{13}, 2003$ ).

Assim, ações de conscientização e valorização da saúde devem ser desenvolvidas desde a pré-escola, quando a criança apresenta uma maior capacidade de absorçáo de informações, podendo incorporar em seus hábitos de vida os cuidados relativos à boca e aos dentes (Fabre $e t$ $\left.a l^{4}, 1998\right)$.

Segundo Fabre et al. ${ }^{4}$ (1998) e Aquilante et $_{\text {al. }}{ }^{3}$ (2003) a criação de hábitos alimentares e de higiene dental deve ser realizada através de métodos adequados ao grau de raciocínio, aprendizagem e psicomotricidade das crianças.

De acordo com Piaget e Gréco ${ }^{11}$ (1974), para construir determinado conhecimento, as concepçôes infantis devem combinar com as informaçóes advindas do meio, e o conhecimento não deverá ser concebido apenas como descoberta espontânea pela criança, nem transmitido de forma mecânica pelo meio exterior ou pelos adultos, mas, como resultado de uma interação, na qual o sujeito será sempre um elemento ativo, que procurará ativamente compreender o mundo que o cerca, e que buscará re- solver as interrogações que esse mundo provoca.

No entanto, segundo Freire et al. ${ }^{5}$ (2000), medidas preventivas têm-se concentrado, principalmente, na modificação do comportamento de crianças durante o processo de educação formal. Esse tipo de ação tem facilitado a operacionalização dos programas preventivos, mas dificultado, em muito, a mudança de hábitos ou atitudes já adquiridas.

Diante disso, a proposta do presente estudo foi avaliar as percepçóes em relação à saúde bucal de crianças do ciclo de Educação Infantil de uma Unidade da rede pública de Ensino de Niterói, RJ.

\section{MATERIAL E MÉTODOS}

Previamente à sua execução, esta pesquisa foi submetida e aprovada pelo comitê de ética local (Parecer 050/06).

Após seleção, por conveniência de uma Unidade de Educação Infantil de Niterói-RJ, foi realizado contato inicial com os responsáveis durante as reuniōes escolares. A estes foi explicado o objetivo do estudo, a importância de sua execução para o meio científico e a importância de sua participação. Estando de acordo com o presente trabalho e com a sua participação e a da criança em uma entrevista, os responsáveis foram solicitados, então, a assinar a autorização por meio do Termo de Consentimento Livre e Esclarecido.

De um total de 68 crianças matriculadas nas 4 turmas do $5^{\circ}$ e $6^{\circ}$ anos da Educaçáo Infantil, 40 (58,8\%) crianças e seus respectivos responsáveis, que estavam presentes durante as reunióes de pais se prontificaram a participar da amostra.

Para a coleta dos dados com as crianças foi utilizado um formulário ilustrado e bastante simples (Figura 1) que poderia ser utilizado com crianças sem alfabetização (Freire et al. ${ }^{6}$, 2002). O objetivo do formulário foi avaliar sua percepção em relação a fatores que fossem positivos à sua higiene e dieta. Este continha figuras dos principais recursos de higiene (escova de dente, creme dental e fio dental) e de alimentos saudáveis (frutas, verduras e legumes) ou não-saudáveis para os dentes (balas, sorvetes, chocolates e bolo).

Para auxiliar o seu preenchimento, foram utilizados elementos reais dos mesmos itens presentes no formulário.

As crianças, após visualizarem a mesa auxiliar e o formulário, foram orientadas, por um único examina- 
dor, em uma sala reservada, a marcar as figuras que são "boas" para os dentes, ou seja, os "amiguinhos dos dentes" (Figura 2).

A fim de melhor caracterizar o grupo de crianças, foi realizada, também, uma entrevista semi-estruturada com os seus respectivos responsáveis. $\mathrm{O}$ formulário da entrevista continha questóes relativas ao nível sócio-econômico-educacional e práticas de higiene e dieta com as crianças.

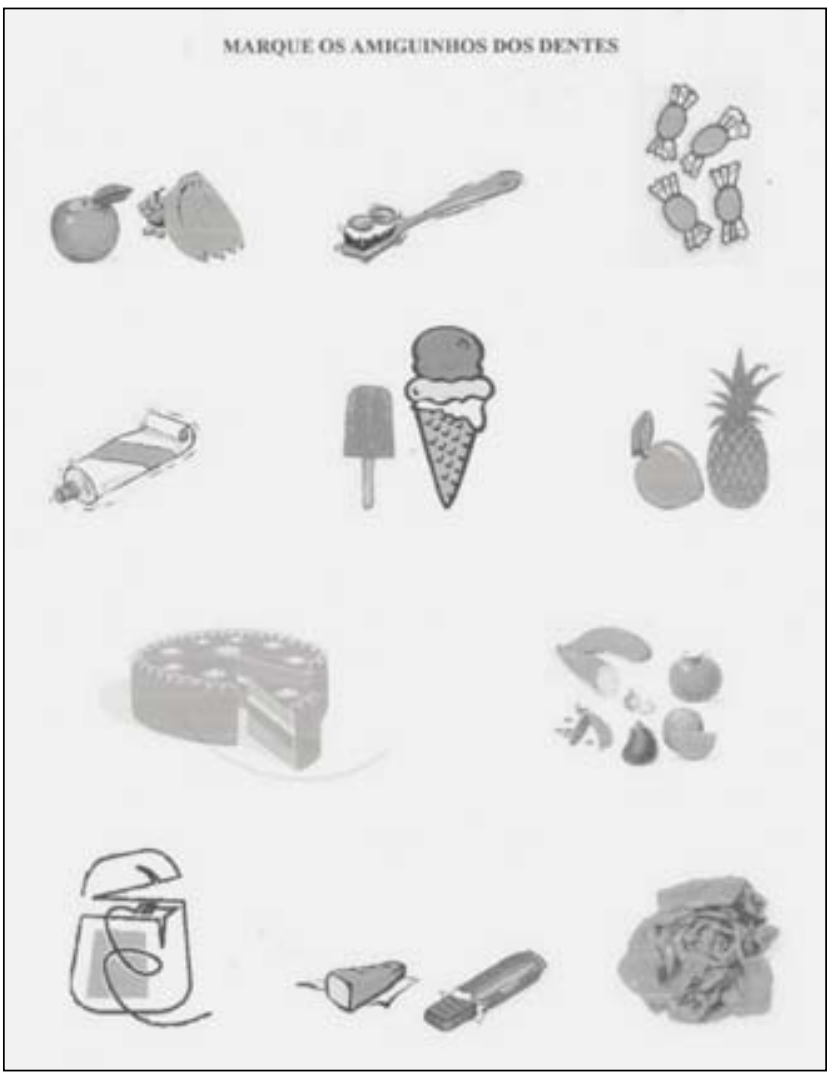

Figura 1- Formulário contendo figuras dos principais recursos de higiene e dos alimentos saudáveis ou não para a saúde bucal.

A metodologia utilizada foi do tipo quanti-qualitativa, a fim de potencializar a análise (Triviños ${ }^{14}, 1987$; Minayo9 ${ }^{9}$ 1999). A análise quantitativa dos dados foi obtida através da freqüência (\%) e do teste Qui-quadrado pelo programa estatístico SPSS 11.0.

\section{RESULTADOS}

Com relação aos responsáveis entrevistados, $70 \%$ eram mães e a média de idade era de 33,08 anos (DP:10,26). A maioria vivia em residência própria (80\%), com uma média de 4,9 pessoas em cada casa. A renda familiar de

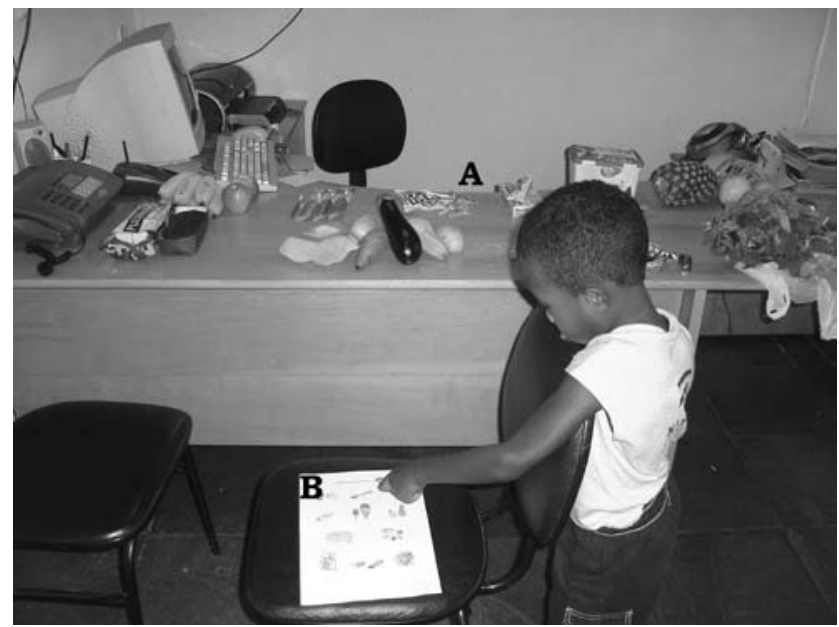

Figura 2 - Elementos reais mostrados em mesa auxiliar para facilitar o preenchimento do formulário contendo figuras dos principais recursos de higiene e dos alimentos saudáveis ou não para a saúde bucal.

$45 \%$ da amostra era de um salário mínimo, enquanto que 35\% recebia entre 1 e 2 salários mínimos. Grande parte dos entrevistados tinha estudado de 5 a 8 anos ou entre a $5^{\mathrm{a}}$ e $8^{\mathrm{a}}$ séries $(47,5 \%)$, seguido pelo $2^{\circ}$ grau ou de 9 a 11 anos de estudo (32,5\%).

Das 40 crianças que compuseram a amostra, 50\% apresentava 4 anos e 50\% 5 anos, e destas, 25 eram do sexo feminino (62,5\%) e 15 do masculino (37,5\%). Em relação aos hábitos de higiene bucal, $35 \%$ das crianças escovavam os dentes sozinhas e apenas $42,5 \%$ dos responsáveis conversavam sempre com a criança sobre a importância da higienização. No que diz respeito ao uso de métodos auxiliares à higienização, pôde-se observar que poucas crianças faziam uso do fio dental $(27,5 \%)$ e de soluções para bochechos (5\%). Sobre a dieta das crianças, foi relatado que a maioria fazia uso diário de leite açucarado (45\%), biscoitos (70\%), sucos $(57,5 \%)$ e balas (35\%), enquanto que poucas se alimentavam diariamente de frutas $(27,5 \%)$, verduras $(22,5 \%)$ e leite sem açúcar (10\%).

No que diz respeito à percepção das crianças sobre a higienização, 97,5\% delas marcaram pelo menos um item de higiene bucal, sendo a escova dental $(92,5 \%)$ e o fio dental $(90 \%)$ os recursos mais selecionados, embora o creme dental também tenha apresentado um alto índice com $87,5 \%$ (Figura 3).

Com relação à dieta, os alimentos saudáveis, como as verduras $(72,5 \%)$, a maçã e a banana $(67,5 \%)$, o abacaxi e a laranja $(65 \%)$ e os legumes $(65 \%)$ foram os mais 
Antunes LS, Antunes LAA, Corvino MPF. Percepção de pré-escolares sobre saúde bucal. Revista de Odontologia da Universidade Cidade de São Paulo 2008 jan-abr; 20(1):52-9

Tabela 1 - Comparação da percepção da criança em relação à higiene e dieta em função da idade.

\begin{tabular}{|c|c|c|c|c|c|c|c|c|c|c|}
\hline \multirow{2}{*}{$\begin{array}{l}\text { Amiguinhos dos dentes } \\
\text { (marcados) }\end{array}$} & \multicolumn{4}{|c|}{4 anos } & \multicolumn{4}{|c|}{5 anos } & \multirow[t]{2}{*}{$\mathrm{X} 2$} & \multirow[t]{2}{*}{ Significância $(P)$} \\
\hline & $\operatorname{sim}$ & $\%$ & não & $\%$ & Sim & $\%$ & não & $\%$ & & \\
\hline${ }^{* *}$ Escova & 19 & 95 & 1 & 5 & 18 & 90 & 2 & 10 & - & $(\mathrm{p}=1,000) \mathrm{ns}$ \\
\hline${ }^{* *}$ Creme dental & 17 & 85 & 3 & 15 & 18 & 90 & 2 & 10 & - & $(\mathrm{p}=1,000) \mathrm{ns}$ \\
\hline **Fio dental & 17 & 85 & 3 & 15 & 19 & 95 & 1 & 5 & - & $(\mathrm{p}=0,605) \mathrm{ns}$ \\
\hline Alimentos saudáveis & sim & $\%$ & não & $\%$ & $\operatorname{sim}$ & $\%$ & não & $\%$ & & \\
\hline *Maçã / banana & 15 & 75 & 5 & 25 & 12 & 60 & 8 & 40 & 1.02 & $(\mathrm{p}=0,311) \mathrm{ns}$ \\
\hline *Abacaxi/Laranja & 14 & 70 & 6 & 30 & 12 & 60 & 8 & 40 & 0.44 & $(\mathrm{p}=0,507) \mathrm{ns}$ \\
\hline${ }^{*}$ Verduras & 14 & 70 & 6 & 30 & 15 & 75 & 5 & 25 & 0.12 & $(\mathrm{p}=0,723) \mathrm{ns}$ \\
\hline *Legumes & 14 & 70 & 6 & 30 & 12 & 60 & 8 & 40 & 0.44 & $(\mathrm{p}=0,507) \mathrm{ns}$ \\
\hline Alimentos não saudáveis & sim & $\%$ & não & $\%$ & $\operatorname{sim}$ & $\%$ & não & $\%$ & & \\
\hline *Balas & 12 & 60 & 8 & 40 & 5 & 25 & 15 & 75 & 5.01 & $(\mathrm{p}=0,025)^{* * *}$ \\
\hline${ }^{*}$ Chocolates & 15 & 75 & 5 & 25 & 7 & 35 & 13 & 65 & 6.46 & $(\mathrm{p}=0,011)^{* * *}$ \\
\hline **Bolo & 16 & 80 & 4 & 20 & 9 & 45 & 11 & 55 & - & $(\mathrm{p}=0,048)^{* * *}$ \\
\hline *Sorvete & 14 & 70 & 6 & 30 & 6 & 30 & 14 & 70 & 6.40 & $(\mathrm{p}=0,011)^{* * *}$ \\
\hline
\end{tabular}

${ }^{*}$ Qui-quadrado (X2) ${ }^{* *}$ Teste Exato de Fisher ${ }^{* * *}$ significativo ao nível de $5 \%$ ns = não significativo

marcados (Figura 4); no entanto, mais da metade das crianças também marcaram o bolo $(62,5 \%)$, os chocolates $(55 \%)$ e os sorvetes $(50 \%)$. As balas ainda foram marcadas por $42,5 \%$ das crianças (Figura 5 ).

Ao se relacionar a marcação dos "amiguinhos dos dentes” com a idade, pôde-se observar que, em relação às crianças com 5 anos de idade, apenas 25\% marcaram as balas, $30 \%$ os sorvetes, $35 \%$ os chocolates e $45 \%$ o bolo, enquanto que para as crianças de 4 anos, as balas foram marcadas por $60 \%$, os sorvetes por $70 \%$, os chocolates por $75 \%$ e o bolo por $80 \%$, apresentando uma diferença estatisticamente significante (Figura 5 e Tabela 1).

Com relaçáo à seleção dos itens que elas consideravam como "amiguinhos dos dentes", as crianças de 4 e 5 anos selecionaram respectivamente: somente itens de higiene ( $5 \%$ e $15 \%)$, itens de higiene e alimentos saudáveis $(5 \%$ e $25 \%)$ e pelo menos um alimento não-saudável (90\% e 60\%) (Tabela 2).

\section{DISCUSSÃO}

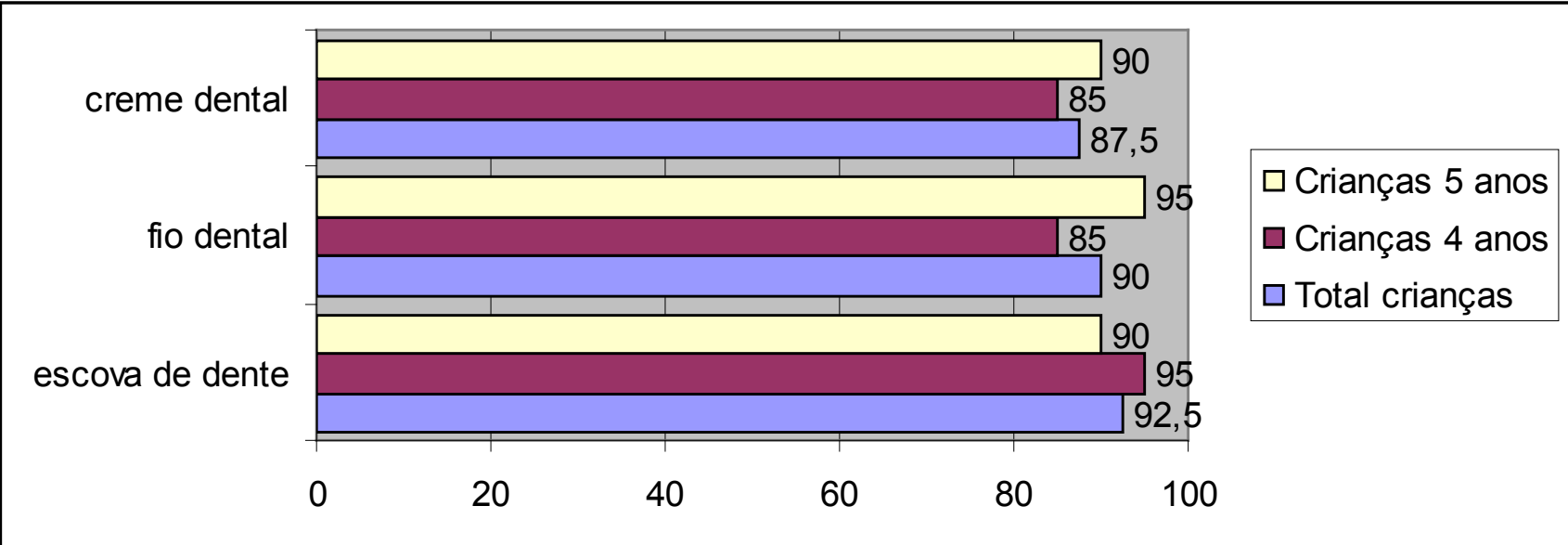

Figura 3 - Distribuição das crianças de acordo com as opçôes selecionadas em relação à higiene. 
Antunes LS, Antunes LAA, Corvino MPF. Percepção de pré-escolares sobre saúde bucal. Revista de Odontologia da Universidade Cidade de São Paulo 2008 jan-abr; 20(1):52-9

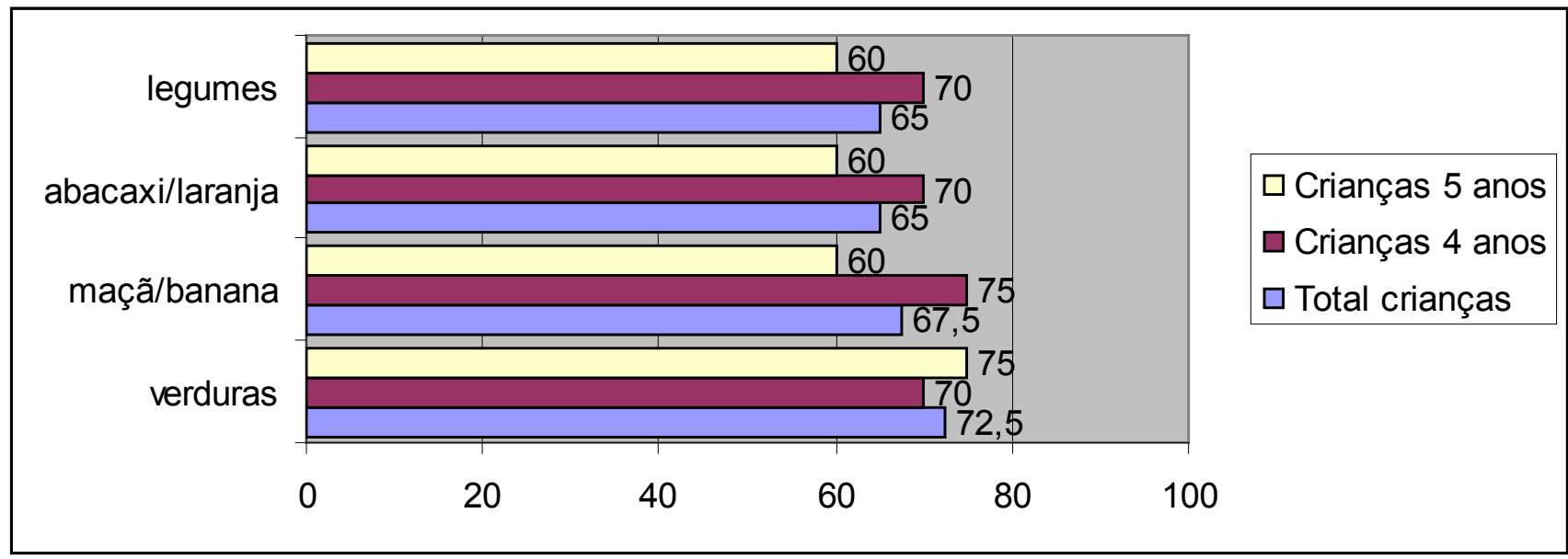

Figura 4 - Distribuição das crianças de acordo com as opçóes selecionadas em relação a alimentos saudáveis.

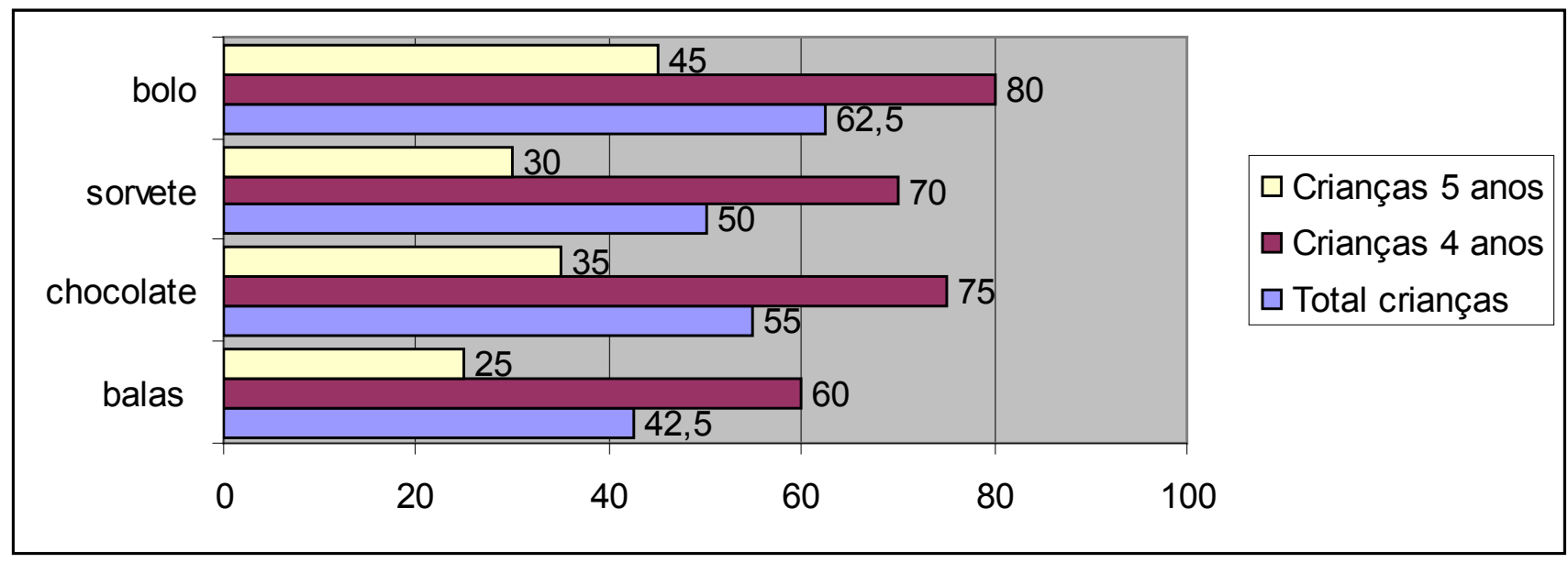

Figura 5 - Distribuição das crianças de acordo com as opçôes selecionadas em relação a alimentos não-saudáveis.

A seleção da amostra nesta pesquisa decorreu, de acordo com a literatura, do fato de serem as crianças em idade pré-escolar mais receptivas à aquisição de novos conhecimentos e estarem numa fase de formação de hábitos de higiene (Aquilante et al. ${ }^{3}$, 2003).

Assim, tomando-se como ponto de partida a percepção das crianças do presente estudo em relação à higienização, pôde-se observar que elas identificaram bem os instrumentos utilizados para a sua realização. Entretanto, em relação à dieta, as respostas foram um tanto contraditórias, uma vez que as crianças também relacionaram a bala, o sorvete, o bolo e o chocolate, na maioria das vezes, como fatores benéficos ao dente. Desse modo, pôdese observar nítida ausência de distinção entre os tipos de alimentos benéficos ou não. Essa falta de capacidade de associar os alimentos e os recursos de higiene também foi encontrada no estudo de Freire et $a l^{6}{ }^{6}$ (2002), no qual apenas $36,7 \%$ das crianças de sua amostra mesmo em outra faixa etária (6-13 anos), fizeram opçóes corretas, assinalando as frutas, juntamente com os recursos de higiene bucal, como "amiguinhos dos dentes".

No presente estudo, a idade foi um fator determinante na marcação das opçóes, e as crianças mais velhas perceberam melhor a importância da dieta para a saúde bucal.

Quanto aos programas educativos em saúde bucal, realizados em escolas públicas brasileiras, é encontrada na literatura quase que exclusivamente a priorização da higienização através do controle da placa, dando-se pouca importância à dieta (Garcia et al. ${ }^{7}, 1998$; Zuanon $e t$ $\left.a l .{ }^{15}, 1999\right)$, fato este que pode estar relacionado à baixa percepção sobre dieta no presente estudo.

Outro fato que pode estar relacionado à ausência, por parte das crianças, do conhecimento sobre dieta seria o 
Tabela 2- Distribuição das crianças de acordo com a seleção dos amiguinhos dos dentes.

\begin{tabular}{|c|c|c|c|c|c|c|}
\hline \multirow{2}{*}{$\begin{array}{l}\text { Opções selecionadas } \\
\text { Higiene bucal }\end{array}$} & \multicolumn{2}{|c|}{ Total crianças } & \multicolumn{2}{|c|}{$\begin{array}{l}\text { Crianças } \\
4 \text { anos }\end{array}$} & \multicolumn{2}{|c|}{$\begin{array}{l}\text { Crianças } \\
5 \text { anos }\end{array}$} \\
\hline & $\mathrm{n}$ & $\%$ & $\mathrm{n}$ & $\%$ & $\mathrm{n}$ & $\%$ \\
\hline Escova, creme e fio dental & 4 & 10 & 1 & 5 & 3 & 15 \\
\hline Total & 4 & 10 & 1 & 5 & 3 & 15 \\
\hline Higiene bucal e alimentos saudáveis & $\mathrm{n}$ & $\%$ & $\mathrm{n}$ & $\%$ & $\mathrm{n}$ & $\%$ \\
\hline Escova, creme, fio dental e 4 saudáveis & 4 & 10 & - & - & 4 & 20 \\
\hline Escova, creme, fio dental e 2 saudáveis & 1 & 2,5 & - & - & 1 & 5 \\
\hline Escova e 1 saudável & 1 & 2,5 & 1 & 5 & - & - \\
\hline Total & 6 & 15 & 1 & 5 & 5 & 25 \\
\hline Higiene bucal e alimentos saudáveis e não-saudáveis & $\mathrm{n}$ & $\%$ & $\mathrm{n}$ & $\%$ & $\mathrm{n}$ & $\%$ \\
\hline Escova, creme, fio dental, 4 saudáveis e 1 não-saudável & 2 & 5 & - & - & 2 & 10 \\
\hline Escova, creme, fio dental, 4 saudáveis e 3 não-saudáveis & 2 & 5 & 1 & 5 & 1 & 5 \\
\hline Escova, creme, fio dental, 4 saudáveis e 4 não-saudáveis & 12 & 30 & 9 & 45 & 3 & 15 \\
\hline Escova, creme, fio dental, 3 saudáveis e 3 não-saudáveis & 3 & 7,5 & 3 & 15 & - & - \\
\hline Escova, creme, fio dental, 3 saudáveis e 1 não-saudável & 3 & 7,5 & 1 & 5 & 2 & 10 \\
\hline Escova, creme, fio dental, 2 saudáveis e 4 não-saudáveis & 1 & 2,5 & 1 & 5 & - & - \\
\hline Escova, creme, fio dental, 1 saudável e 4 não-saudáveis & 1 & 2,5 & - & - & 1 & 5 \\
\hline Escova, creme, fio dental e 3 nâo-saudáveis & 1 & 2,5 & 1 & 5 & - & - \\
\hline Escova, fio dental, 1 saudável e 1 não-saudável & 1 & 2,5 & - & - & 1 & 5 \\
\hline Escova, 2 saudáveis e 1 não-saudável & 1 & 2,5 & 1 & 5 & - & - \\
\hline Creme e 1 saudável e 2 não-saudáveis & 1 & 2,5 & - & - & 1 & 5 \\
\hline Fio dental e 1 não-saudável & 1 & 2,5 & - & - & 1 & 5 \\
\hline Nenhum item & 1 & 2,5 & 1 & 5 & - & - \\
\hline Total & 30 & 75 & 18 & 90 & 12 & 60 \\
\hline
\end{tabular}

conhecimento de seus professores em relação ao assunto (Antunes et al. ${ }^{2}, 2006$ ) e as práticas deficientes de seus familiares relacionadas à saúde bucal da criança, como o observado nesta pesquisa.

Nesse contexto, a realização de programas de treinamento e aperfeiçoamento de professores com informaçôes atuais e cientificamente corretas sobre saúde bucal se torna necessária para contribuir de forma efetiva na implementação dos citados programas de saúde bucal nas escolas, desde que fundamentados no interesse, na motivação e no conhecimento daqueles profissionais (Fabre et al. ${ }^{4}, 1998$; Antunes et al. ${ }^{2}, 2006$ ).

Para Piaget, as atividades realizadas na pré-escola devem ser desenvolvidas através de atividades em grupos, coordenadas ou não pelo professor, mas de preferência sem a interferência deste, tal que possam, entre si, brincar, falar, discutir, resolver problemas práticos. A passagem da ação à operação exige a possibilidade de a criança reconstruir suas ações no plano da representação, descentrar-se de seu próprio ponto de vista ou de sua ação e enfrentar o julgamento e aceitar a cooperação do grupo. Por isto, Piaget considera que o segundo aspecto importante da educação pré-escolar é o desenvolvimento de habilidades de comunicação. Isto é, agora não basta mais à criança realizar as açóes, é preciso que ela fale delas para outrem, que as reconstitua por via narrativa e que aprenda a descrevê-las, em palavras, quadros e desenhos. Por isto, tanto do ponto de vista da socializaçáo da criança como de seu desenvolvimento intelectual, é importante que tenha experiência de trabalho em equipe (Piaget $^{10}, 1971$; Piaget ${ }^{12}, 1975$ ).

O professor de pré-escola tem o conhecimento de que a criança entre dois e seis anos explora ativamente pela ação e que sua inteligência se manifesta cada vez mais e melhor nesse plano. O que é observado é, de um lado, uma presença paralela das representações e, de ou- 
tro, uma crescente melhoria delas, mormente no campo de regulações perceptivas e intuitivas, como o observado no presente estudo. Em outras palavras, a criança nesse período sofistica a atividade sensório-motora (corre, pula, afasta-se cada vez mais de seu ambiente familiar, pode ir e voltar de um lugar a outro com segurança etc.) e ao mesmo tempo constrói progressivamente seus hábitos que serão levados no decorrer de sua vida (Macedo ${ }^{8}$, 1994).

\section{CONCLUSÃO}

Baseando-se neste estudo, fica clara a necessidade de:

- Inclusão de conteúdos relacionados à saúde bucal nos currículos escolares da educação infantil, a fim de favorecer a abordagem desse tema, tanto em sala de aula quanto para servir como elo nas atividades com a comunidade;

- Urge capacitar professores, através de programas de saúde bucal, para estimularem a formação de hábitos saudáveis, tanto com as crianças quanto com suas famílias;

- É necessário prover maior envolvimento da família nas atividades realizadas na escola, através de sua conscientização, visando mudanças de comportamento e uma maior participação nas atividades da criança;

- É fundamental propiciar uma maior interação com o dentista, através de programas de educação em saúde que busquem o desenvolvimento de atividades integradas com professores e alunos.

\section{REFERÊNCIAS}

1. American Academy of Pediatric Dentistry. Definition of dental neglect. Pediatr Dent; 1995-1996; 17(6):26.

2. Antunes LS, Soraggi MBS, Antunes LAA, Corvino MPF. Avaliação da percepção das crianças e conhecimento dos educadores frente à saúde bucal, dieta e higiene. Pesqui Bras Odontopediatria Clín Integr, 2006 Jan-Abr; 6(1):71-7.

3. Aquilante AG, Almeida BS, Martins De Castro RF, Xavier CRG, Sales Peres SHC, Bastos JRM. A importância da educação em saúde bucal para préescolares. Rev. Odontol UNESP, 2003 Jan-Jul; 32(1): $39-45$.

4. Fabre RC, Vilela EM, Biffi EM. Programa de prevenção e educação em saúde bucal para crianças de 3 a 5 anos: um relato de experiência. Rev do CROMG 1998 Jul-Dez; 4(2): 101-7.

5. Freire MCM, Macêdo RA, Silva WH. Conhecimentos, atitudes e práticas dos médicos pediatras em relação a saúde bucal. Pesqui odontol bras, 2000 Jan-Mar; 14(1): 39-45.
6. Freire MCM, Soares FF, Pereira MF. Conhecimentos sobre Saúde Dental, Dieta e Higiene Bucal de Crianças Atendidas pela Faculdade de Odontologia da Universidade Federal de Goiás. JBP J Bras Odontopediatr Odontol Bebê, 2002 mai-jun; 5(25)195-9.

7. Garcia PPNS, Corona SAM, Valsecki Junior A. Educação e motivação II. Avaliação da efetividade de métodos educativos-preventivos relativos a cárie dental e a doença periodontal. Rev. Odontol. UNESP 1998 Jul-Dez; 27(2):405-15.

8. Macedo L. A perspectiva de Jean Piaget. Série Idéias n. 2. São Paulo: FDE, 1994. p. 47-51.

9. Minayo MCS. Fase de análise ou tratamento do material. In: O desafio do conhecimento. Rio de Janeiro: Hucitec-Abrasco,1999. p. 197-247.

10. Piaget J. A formação do símbolo na criança: imitação, jogo e sonho, imagem e representação. Rio de Janeiro: Zahar, 1971.

11. Piaget J, Gréco P. Aprendizagem e conhecimento. São Paulo: Freitas, 1974.

12. Piaget J. Los años postergados: la primeva infancia. Buenos Aires: Pardós, 1975. 
13. Pomarico L, Souza IPR, Tura LFR. Oral health profile of education and health professionals attending handicapped children. Pesqui odontol bras, 2003 JanMar; 17(1): 11-6.

14. Triviños Ans. Pesquisa qualitativa. In: Introdução à pesquisa em ciências sociais. São Paulo: Atlas, 1987. p. 116-174.
15. Zuanon ACC, Malagoli DM, Giro EMA. A importância de reforço constante na motivação do paciente. JBP J Bras. Odontopediatr. Odontol. Bebê, 1999; 2(9): 391-6.

Recebido em: 04/04/2007

Aceito em: 18/11/2007 